\title{
Epidemiology and financial impact of bovine mastitis in an animal production and research center and small holder dairy farms in horoguduru wollega zone, western Ethiopia
}

\begin{abstract}
Mastitis is inflammation of parenchyma of the mammary gland regardless of the causative agent. The objective of this study was to determine the prevalence, risk factors and financial losses caused by mastitis in six small holder dairy farms and the Animal Production and Research Center of the Wollega University. Data was collected through a questionaire on extrinsic and intrinsic risk factors and financial loss for one year production cycle. Sub-clinical mastitis prevalence was diagnosed using the California Mastitis test (CMT). Chi square, univariable and multivariable logistic regression methods were used to determine the risk factors of the disease. CMT's were done on 154 lactating cows. The result of the study showed a prevalence rate of $46.75 \%$, with $36.36 \%$ subclinical and $10.39 \%$ clinical mastitis cases. The analysis of extrinsic risk factors showed the management system is poor for most farms. Multivariable logistic regression showed breed, age and lactation status are the main risk factors that contribute for occurrence of the disease. When all farms were put together, the disease caused total loss of 2,949.8USD $(59,719.08 \mathrm{ETB})$, with an average annual milk loss of $22.3 \%$ in cross breed and $2.24 \%$ in local zebu cattle., Results of this study showed a high mastitis prevalence rate resulting in significant milk production and economic losses. Factors identified which may have played a role include dairy cow management, breed, age and lactation status. Recommendations to address these problems should be made awareness creation for the dairy cow owners on housing and management of dairy cow; awareness creation for the dairy cow owners on sources of mastitis pathogen and transmission methods of mastitis causing agent; design and implementation of control methods and further investigation of the disease by researcher were recommended.
\end{abstract}

Keywords: cross breeds, financial impact, horoguduru animal production and research center, mastitis, risk factor, prevalence, shambu, california mastitis test
Volume 5 Issue 4 - 2017

\author{
Belay Beyene,' Tadele Tolosa ${ }^{2}$ \\ 'Department of Animal Science,Wollega University, Ethiopia \\ 2Department of Microbiology and Veterinary Public Health, \\ limma University, Ethiopia
}

\author{
Correspondence: Belay Beyene, Department of Animal \\ Science, Wollega University, Shambu Campus, P.O. Box, 38 \\ Shambu, Ethiopia, Tel +2510 913245416 , \\ Email belaybwak@gmail.com
}

Received: November 25, 2016 | Published: June 30, 2017

\section{Introduction}

To increase milk production cross breeding of indigenous zebu with exotic breeds like Jersy with Zebu and Jersy with Zebu are done in many African countries This results in a larger portion of the mixed breed cattle being used for milk production in urban areas. However, dairy production is subjected to diseases' of intensification like mastitis and reproductive disorders. ${ }^{1}$ Mastitis is inflammation of the parenchyma of the mammary gland regardless of the causative agent. ${ }^{2-4}$ It is characterized by a range of physical and chemical changes in the milk and pathological changes in the glandular tissue. ${ }^{3,5}$ The most important changes are discoloration of milk, the emergence of clots in milk; swelling, heat, pain and edema in the mammary gland of clinical cases. ${ }^{3}$ Isolation from the natural disease or experimental investigation showed that several species of bacteria, fungi, mycoplasmas and algae have been considered as causes of bovine mastitis though bacteria are the major ones. ${ }^{5}$

Mastitis also results in economic losses to the farmer through decreased milk production during remainder of lactation due to udder damage in case of subclinical infection. In addition to this it increases the culling and replacement rates leading to loss of genetic potential and deaths of diseased animals. ${ }^{4}$ The same authors stated that mastitis causes $30 \%$ reduction in productivity per affected quarter and a $15 \%$ reduction in productive cow/lactation, which make the disease one of the most serious problems affecting the dairy industry worldwide.

In Ethiopia, previously many studies of bovine mastitis were concentrated in around? large towns and in central Ethiopia. ${ }^{1}$ There was not any study conducted on bovine mastitis in the present study area. The aims of the animal production and research center of Wollega University are to produce Horo breed crossed with Jersey as well as Horo crossed with Holstein Friesian and then distribute F1 crosses of these mixed breeds to the community. However, Data of veterinary clinic from those districts and Question from the society indicated Mastitis is the main problem for dairy cow.

However, the case report in the veterinary clinic and community problem appraisal indicates the presence of the disease and economic effect of mastitis in the area. Therefore, the objectives of the study were:

i. To determine the prevalence of subclinical and clinical mastitis,

ii. Investigate management and animal level risk factors that favor occurrences of mastitis and

iii. To estimate financial losses incurred to the farm due to mastitis. 


\section{Material and methods}

\section{Study area}

HoroGuduru Wollega Zone is located in the western part of Oromia regional state of Ethiopia. The livelihood of farmers in the area is depending on livestock rearing and crop production. In this study, two towns, namely; Shambu in Horo district and Finch of Abayichoman and Horo guduru Animal Production and Research Center in Guduru district were selected. Selection was based on the types of farming (Extensive, semi intensive and intensive grazing system; Housing system cows were housed on either earth floors without shade, a concrete floor with shade or a stone floor with shade) Milking system all animals were milked manually in those districts and the existences of smallholder dairy production and bovine mastitis was not studied before.

\section{Study group}

Animals in smallholder dairy farms of Shambu, Fincha, dairy farm of Wollega University Shambu Campus and Horoguduru Research Center of Wollega University were considered as target population and the lactating cows in those dairy farms were the study population. Milk samples were collected from 154 total lactating cows of different lactation status from the study population (Table 1).

\section{Methods of data and sample collection}

Questionnaire: A well designed questionnaire ${ }^{6}$ was developed and administered to the dairy owners or managers by the researcher in person. The managers or heads of the house hold were the active respondents for the data requested. Animal data were collected from records and through interviewing responsible personnel. To estimate financial losses due to mastitis, retrospective data over a period of 1year on mastitis cases? Prevalence?, (one case?) treatment cost/animal breed? And milk discarded during the treatment were collected.

Collection and examination of milk sample: Milk samples were collected from total number of lactating cows in Shambu $(n=39)$, Fincha $(\mathrm{n}=13)$, Wollega University Shambu campus $(\mathrm{n}=6)$ and HoroGuduru animal production and research center of Wollega University $(n=96)$. Cows were sampled once only. Strict aseptic procedures like washing of teats with soap and water, drying with towel and application of $70 \%$ ethyl alcohol were used while collecting milk samples in order to prevent contamination with microorganisms present on the skin of cow's flanks, udder and teats, on the hands of the sampler, and in the barn environment. ${ }^{3}$ The California Mastitis Test (CMT) was carried out on every milk sample to determine the prevalence of mastitis at cow and quarter level. ${ }^{3}$ About $2 \mathrm{ml}$ from each quarter was placed in each of four shallow cups in the CMT paddle. An equal amount of the commercial CMT reagent was added to each cup. A gentle circular motion was applied to the mixtures, in a horizontal plane for $15 \mathrm{sec}$. The reaction was interpreted according to Quinn et al., ${ }^{3}$ Pandey \& Voskuil. ${ }^{7}$ The average duration of lactation of 240days for local zebu cows (with a range of 210-270days) and of 305days for crossbreds (with a range of 305-408days) were used as the average lactation lengths. ${ }^{8}$ The average milk off-take per lactation is estimated to be 323 liters (L) (range of 276-376L) for local zebu cattle and 3694L (range of 3473-3915L) for crossbred cattle. ${ }^{8}$

\section{Data analysis}

All collected data were entered into Microsoft excel spreadsheet. Data was cleaned and descriptive statistics were performed on Microsoft excel spread sheet. The prevalence of clinical and subclinical mastitis were the dependent variables while the herd level, cow level and quarter level variable were considered as independent variables. The independent variables at herd level included barn floor status (dust made, stone made and concrete made), milking hygiene (washing hands before and after milking (yes or no)) and grazing system (Extensive, semi intensive and intensive). While the independent variable at cow-level included the breeds( local and cross breed), age (2,5-6year, 6-9,5year and $>9.5$ year), parity status $(1-3$ calf, $3-6$ calf and $>6$ calf lactation status ( $\leq 3$ month, $3-6$ month and $>6$ month)and average milk yield. The total Prevalence was calculated as the sum of clinical mastitis and CMT positive sub clinical mastitis divided into the total lactating cows. Sub clinical mastitis is the inflammation of mammary gland that is clinically not apparent and infection is detected by milk diagnostic tests. ${ }^{5}$ Prevalence of Sub clinical mastitis was calculated by CMT positive but clinically non observable mastitis divide by total examined lactating cows. Clinical mastitis is characterized by swelling, heat, pain and edema in the mammary gland, discoloration of milk and the presence of clots in milk. ${ }^{3}$ Prevalence of Clinical mastitis was calculated by clinically observable mastitis divide by total examined lactating cow. The associations between dependent and independent variables were tested by chi-square test, Univariable logistic regression and multivariable logistic regression models. Odd ratio and confidence intervals were used to measure level of association.

Quarter was defined as CMT positive if it had a CMT score of $1+$ or above. A lactating cow was defined mastitis positive if it had at least one quarter with a CMT score of,,++++++ or clinically observable signs like pus releasing, blood mixed milk or blinded teat. ${ }^{3}$ In this study nine factors(Washing of hand before milking start, washing of hand between milking of cows, use of towel, grazing type, washing hand between milking cows, breed, lactation status, age and number of parity) were considered as risk factors for occurrence of mastitis in the study area (Table 1) (Table 2). From those factors, four were statistically significant at analysis of chi-square and univariable logistic regression (breed, lactation status, age and number of parity). Based Grimes \& Schulz ${ }^{9}$ after analysis of univariable logistic regression all factors that are considered biologically as predictor variables and have $\mathrm{P}<0.15$ were subjected to multivariable logistic regression analysis to construct the likely model $(\mathrm{P}<0.05)$ by forward selection method. The overall fitness of the model was assessed using maximum likelihood (probability) estimation. ${ }^{6}$ From the four factors entered into multivariable, three factors (breed, lactation status and age) were statistically significant $(\mathrm{p}<0.05)$ (Table 3$)$. Those factors significant in univariable logistic regression $(\mathrm{P}<0.05)$ and insignificant in multivariable logistic regression were considered as confounding. Whereas, those factors significant at all level of analysis (ch-square, univariable logostic regression and multivariable logistic regression were considered as risk factors for the occurrence of Mastitis in the study area).

In financial losses estimation, the total loss was calculated as

$\mathrm{C}=\mathrm{Md}+\mathrm{Ct}$

Where, C: Total Financial Losses

Md: Milk discarded due to mastitis

Ct: Treatment cost. ${ }^{10,11}$

Percentage of annual Production losses was calculated by dividing total annual production losses due to mastitis to total annual production without mastitis. 
Percentage of annual losses $=\left(\frac{\text { total annual production losses due to mastitis }}{\text { total annual production with out mastitis }}\right) x 100$

SPSS version 20 and SAS 9.2 software were used to analysis the data. In all cases the $95 \%$ confidence interval and $5 \%$ level of precision were applied.

Table I Descriptive statistics of cow level risk factors and prevalence of mastitis in smallholder dairy cows in HoroGuduruWollega zone

\begin{tabular}{lllllll}
\hline Variable & Tested cow & Test positive(\%) & Prevalence & Cl95\% & $\mathbf{x}^{2}$ & P-value \\
\hline Breed & & & & & \\
Local & 89 & $34(38.20)$ & & $32.17-44.23$ & 6.193 & 0.01 \\
Cross & 65 & $38(58.46)$ & & $49.23-67.69$ & & \\
Lactation & & & & & \\
<3month & 38 & $13(34.21)$ & & $28.81-39.61$ & 9.764 & 0.044 \\
3-6Month & 34 & 13 & 38.24 & $32.19-44.27$ & & \\
$>6$ Month & 82 & 46 & 56.1 & $47.24-64.95$ & & \\
Age(in year) & & & & & \\
2.5-6 & 41 & 14 & 34.15 & $28.75-39.54$ & 10.003 & \\
6-9.5 & 46 & 17 & 36.96 & $31.12-42.79$ & & 0.007 \\
$>9.5$ & 67 & 41 & 61.19 & $51.53-70.86$ & & \\
Number of Parity & & & & & \\
3-Jan & 77 & 28 & 36.36 & $30.6-42.1$ & 9.26 & 0.01 \\
6-Mar & 61 & 32 & 52.46 & $44.2-60.7$ & & \\
$>6$ & 16 & 12 & 75 & $63.2-86.7$ & & \\
\hline
\end{tabular}

Table 2 Management system of smallholder dairy cows in HoroGuduruWollega Zone

\begin{tabular}{|c|c|c|c|c|c|}
\hline $\begin{array}{l}\text { Management } \\
\text { system }\end{array}$ & Number of dairy farms & Number of tested cows (\%) & Test positive (\%) & $x^{2}$ & P-value 95\% \\
\hline \multicolumn{6}{|c|}{ Washing hand between milking } \\
\hline Yes & 4 & I33 (86.36) & $62(46.62)$ & 0.93 & 0.56 \\
\hline No & 5 & $21(13.64)$ & $10(47.62)$ & & \\
\hline \multicolumn{3}{|c|}{ Use of towel in cleaning teat after washing } & & 0.46 & 0.788 \\
\hline Common Towel & & |3| (85.06) & $60(45.8)$ & & \\
\hline Separate Towel & & $18(11.69)$ & $9(50)$ & & \\
\hline No use of Towel & & $5(3.25)$ & $3(60)$ & & \\
\hline \multicolumn{3}{|c|}{ Washing hand before milking start in farm } & & 0.41 & 0.29 \\
\hline Yes & 6 & 140 (90.9I) & $64(45.7 \mathrm{I})$ & & \\
\hline No & 3 & $14(9.09)$ & $8(57.14)$ & & \\
\hline \multicolumn{2}{|l|}{ Grazing type } & & & 2.93 & 0.23 \\
\hline Extensive & 2 & $99(64.29)$ & $42(42.42)$ & & \\
\hline Semi Intensive & 6 & $54(35.06)$ & $29(53.7)$ & & \\
\hline Intensive & 1 & I $(0.65)$ & $I(100)$ & & \\
\hline \multicolumn{2}{|l|}{ Floor type } & & & 2.02 & 0.36 \\
\hline Concrete & 4 & $49(31.82)$ & $24(48.98)$ & & \\
\hline Dust & 1 & 96 (62.34) & $4 \mid$ (42.7I) & & \\
\hline
\end{tabular}


Table 3 Multivariable logistic regression of management and cow risk of smallholder dairy farm in HoroGuduru Wollega Zone

\begin{tabular}{|c|c|c|c|c|c|c|}
\hline Parameter & B & S.E. & Walda & $\operatorname{Exp}(B)$ & 95\% C.I. for EXP(B) & P-Value -95\% \\
\hline \multicolumn{7}{|c|}{ Grazing system } \\
\hline Extensive & Reference & & & & & \\
\hline Semi intensive & $2.94 I$ & 2.419 & 1.478 & 18.93 & $0.165-.226$ & 0.224 \\
\hline Intensive & 20.886 & 40192.97 & 0 & 0.001 & $0.00 I-0.01$ & $\mathrm{I}$ \\
\hline \multicolumn{7}{|l|}{ Types of floor } \\
\hline Concrete & Reference & & & & & \\
\hline Stone made & 0.147 & 1.655 & 0.008 & 1.158 & $0.045-29.6$ & 0.929 \\
\hline Dust made & -2.063 & 1.631 & 1.601 & 0.127 & $0.005-3.1$ & 0.206 \\
\hline \multicolumn{7}{|c|}{ Washing hand before milking } \\
\hline \multicolumn{7}{|l|}{ Yes } \\
\hline No & 0.865 & 1.44 & 0.36 & 2.374 & $0.141-39.9$ & 0.548 \\
\hline \multicolumn{7}{|l|}{ Breed } \\
\hline Local breeds & Reference & & & & & \\
\hline Cross breeds & 3.283 & 1.003 & $|0.7| \mid$ & 26.647 & $3.73-45$ & 0.001 \\
\hline \multicolumn{7}{|l|}{ Age (in year) } \\
\hline $2.5-6$ & Reference & & & & & \\
\hline $6-9.5$ & -2.699 & 0.806 & 11.229 & 0.067 & $0.014-0.326$ & 0.001 \\
\hline$>9.5$ & -2.214 & 0.652 & || $.52 \mid$ & 0.109 & $0.030-0.392$ & 0.001 \\
\hline \multicolumn{7}{|c|}{ Number of calving } \\
\hline & Reference & & 2.23 & & & 0.328 \\
\hline$>3-6$ & -0.967 & 0.776 & 1.554 & 0.38 & $0.083-1.74$ & 0.213 \\
\hline$>6$ & -1.14 & 0.767 & 2.21 & 0.32 & $0.07|-| .437$ & 0.137 \\
\hline \multicolumn{7}{|l|}{ Lactation } \\
\hline$<3$ month & Reference & & 6.856 & & & 0.032 \\
\hline 3-6Month & -1.161 & 0.486 & 5.709 & 0.313 & $0.120-0.812$ & 0.017 \\
\hline$>6$ Month & -0.884 & 0.503 & 3.095 & 1.12 & I.05-I.34 & 0.012 \\
\hline
\end{tabular}

\section{Result}

The production system of dairy cows in the study area includes intensive, semi-intensive and extensive types. Our result revealed that $64.29 \%, 35.06 \%$ and $0.65 \%$ of the dairy cows were kept under extensive, semi intensive and intensive grazing system consecutively. The current study reported that $5.84 \%, 31.82 \%$ and $62.34 \%$ of the dairy cows are kept in housing in which the flooring consisted of stone earth with no roofing or a concrete floor with metal sheet roof (Table 2).

\section{Prevalence}

The current study revealed 72/154 (46.75\%; CI95\%, 39.37-54.13) cows had at least one quarter positive to mastitis. From the total of 616 quarters examined $141(22.89 \%$; 95\% CI, 21.08-24.7) were positive to mastitis. From the total of 141 infected quarters, 94 quarters $(15.26 \%$; $95 \%$ CI, $14.05 \%-16.46 \%$ ) were sub clinically positive to CMT and 47 quarters $(7.63 \%$; CI95\%,7.03\%-8.23\%) were clinically infected. The finding showed of the 37 clinically infected cows, 27 have single infected quarter and 10 cows have two clinically infected quarters. In this study there is no cow with more than two quarter infected with

mastitis. The study also found that of the total of clinically infected quarters $13(2.1 \%$; 95\% CI, $1.94 \%-2.28 \%)$ teats were blind. The Quarter level prevalence showed, that 5 cows with clinical mastitis had total blind teats $(3.25 \% ; 2.73-3.7795 \% \mathrm{CI}), 4$ of these cows have single blind teats $(2.61 \%$; $95 \% \mathrm{CI}, 2.19 \%-3.01 \%)$. However, there is no cow with more than two blind teats (Table 4).

\section{Risk factors}

Chi-square was used to analysis the presence of association between potential risk factors and occurrence of mastitis. The result showed that difference in breed, stage of lactation, age of animal and parity has a significant effect on the occurrence of mastitis in dairy cows (Table 1). The univariable logistic regression analysis showed that cross breed dairy cows were more than 2.3times more at risk of developing mastitis than local breed cows. The result also showed that an increase in age also significantly increase in prevalence of mastitis. Similarly, as the number of parities increased the risk of mastitis also increased (Table 5). Multivariable logistic regression showed that breed of animals, age and lactation status are the main risk factors and have cause effect relationship for prevalence of mastitis. However, the effect of number of parity was considered as bias. 


\section{Financial losses}

Based on average duration of lactation of 240days for local zebu cows and 305 days for crossbreds and average milk production per lactation is estimated to be 323liters (L) for local zebu cattle and 3694L for crossbred cattle. ${ }^{8}$ Using these reported values as standards then this study showed average annual milk losses of cross breed dairy cow to be $22.3 \%$ and $2.24 \%$ in local zebu dairy cows. The study also showed that milk discarded due to mastitis treatments was due to drug

Table 4 Cow and teat level prevalence of sub clinical and clinical mastitis in HoroGuduruWollega Zone

\begin{tabular}{llll}
\hline Factor & CMT & Prevalence(\%) & $\mathbf{9 5 \%} \mathbf{C l}$ \\
\hline Cow level & & & \\
Sub Clinical & 56 & 36.36 & $30.62-42.11$ \\
Clinical & 16 & 10.39 & $8.74-12.03$ \\
Total & 72 & 46.75 & $39.37-54.14$ \\
Teat & & & \\
Subclinical & 94 & 15.26 & $14.05-16.46$ \\
Clinical & 47 & 7.63 & $7.03-8.23$ \\
Blind teat & 13 & 2.1 & $1.94-2.28$ \\
Total & 141 & 22.89 & $21.08-24.7$ \\
Clinically infected quarter & $\mathbf{N u m b e r}$ cow & $\mathbf{P r e v a l e n c e ~ ( \% ) ~}$ & $95 \% \mathbf{C l}$ \\
One quarter & 27 & 17.53 & $14.76-17.53$ \\
Two quarter & 10 & 6.49 & $5.47-7.52$ \\
Three quarter & 0 & 0 & 0 \\
Four quarter & 0 & 0 & 0 \\
Blind teat & & & $2.73-3.25$ \\
One quarter & 5 & 2.6 & $2.19-3.01$ \\
Two quarter & 4 & 0 & 0 \\
Thee quarter & 0 & 0 & 0 \\
Four Quarter & 0 & 3.25 & \\
\hline
\end{tabular}

Table 5 Univariable logistic regression analysis of cow level risk factors of mastitis in smallholder dairy cows in HoroGuduruWollega Zone

\begin{tabular}{|c|c|c|c|c|c|c|}
\hline Variable & B & S.E. & Wald & P-value & $\operatorname{Exp}(B)$ & 95\% C.I. EXP(B) \\
\hline \multicolumn{4}{|l|}{ Breed } & 0.014 & 2.28 & I.19-4.37 \\
\hline Local & Ref & & & & & \\
\hline Cross & 0.823 & 0.333 & 6.1 & & & \\
\hline \multicolumn{4}{|c|}{ Age (in year) } & 0.008 & 1.6 & I.35-I.85 \\
\hline $2.5-6$ & Ref & & & & & \\
\hline$>6-9.5$ & 1.112 & 0.414 & 7.22 & & & \\
\hline$>9.5$ & 0.99 & 0.395 & 6.27 & & & \\
\hline \multicolumn{7}{|c|}{ No of parity } \\
\hline 3-Jan & 1.66 & 0.624 & 8.6 & 0.014 & 3 & $2.52-3.47$ \\
\hline$>3-6$ & I & 0.632 & 7.06 & 0.008 & 0.19 & \\
\hline$>6$ & & 0.577 & 2.51 & 0.113 & 0.368 & \\
\hline \multicolumn{7}{|c|}{ Lactation status } \\
\hline$<3$ month & Ref & & & & 1.28 & I.08-I.48 \\
\hline 3-6Month & 0.899 & 0.408 & 4.86 & 0.028 & & \\
\hline$>6$ Month & 0.725 & 0.417 & 3.02 & 0.082 & 0.407 & \\
\hline
\end{tabular}

Citation: Beyene B, Tolosa T. Epidemiology and financial impact of bovine mastitis in an animal production and research center and small holder dairy farms in horoguduru wollega zone, western Ethiopia.J Dairy Vet Anim Res. 20 I7;5(4):I44-I5I. DOI: I0.I5406/jdvar.2017.05.00I52 
Table 6 Milk discarded during treatment and its losses in smallholder dairy cows in Horoguduru Wollega Zone

\begin{tabular}{lllll}
\hline Breed & $\begin{array}{l}\text { Number of } \\
\text { animal treated }\end{array}$ & $\begin{array}{l}\text { Total day } \\
\text { of milk } \\
\text { discarded }\end{array}$ & $\begin{array}{l}\text { Amount of milk } \\
\text { discarded } \\
\text { (in liter) }\end{array}$ & $\begin{array}{l}\text { Average losses due to milk } \\
\text { discarded in ethiopia }\end{array}$ \\
\hline $\begin{array}{l}\text { Cross } \\
\text { Breeds }\end{array}$ & 61 & 416 & 5038.37 & 52,903 \\
$\begin{array}{l}\text { Local } \\
\text { Breeds }\end{array}$ & 44 & 44 & 59.22 & 621.81 \\
motal & 105 & 460 & 5097.59 & 53,525 \\
\hline
\end{tabular}

Table 7 Average cost incurred to the owner due to treating of clinical mastitis in HoroGuduruWollega zone

\begin{tabular}{lllcr}
\hline Name of drugs & unit & $\begin{array}{l}\text { Total amount of drugs used for } \\
\text { treatment }\end{array}$ & Cost in ethiopian birr & Cost in (USD) \\
\hline Penstrip & $\mathrm{ml}$ & $148 \mathrm{I}$ & 1073.7 & 53.02 \\
Oxytetracycline 10\% & $\mathrm{ml}$ & 186 & 72.54 & 3.58 \\
Oxytetracycline 20\% & $\mathrm{ml}$ & 36 & 15.84 & 0.78 \\
Intramammary infusion & Ampoule & 272 & 5032 & 248.49 \\
Total & & & $6,194.08$ & 305.88 \\
\hline
\end{tabular}

\section{Discussion}

\section{Prevalence}

The total prevalence $72 / 154(46.75 \%, 95 \% \mathrm{CI}, 39.37-54.14)$ is comparable with $52.78 \%$ overall prevalence reported by Sori et al. ${ }^{12}$ from Sebeta Town of Ethiopia and 50\% from most countries of the world. ${ }^{3}$ The result was lower than the $71 \%$ reported by Mekibab et al. ${ }^{13}$ from Holeta town, central Ethiopia. However; it was higher than the $23.18 \%$ report of Girma et al..$^{9}$ from Hararge of eastern Ethiopia. That study was done on lactating Zebu cows. The clinical mastitis prevalence of $16 / 154(10.39 \%, 95 \% \mathrm{CI}, 8.74-12.03)$ is in agreement with the $11.9 \%$ reported by Biffa et al. ${ }^{14}$ In this study clinical mastitis is higher than $6.6 \%$ reported by Almaw et al. ${ }^{1}$ and the $4.9 \%$ report by Moges et al. ${ }^{15}$ Our results showing $36.36 \%$ cow level subclinical mastitis is in agreement with $36.67 \%$ of Sebeta Sori et al. ${ }^{12} 31.0 \%$ from Hawassa of the southern region ${ }^{16}$ and $40.6 \%$ of Batu and its surrounding area. ${ }^{17}$ A previous report of $48.6 \%{ }^{13}$ on the prevalence of subclinical mastitis was higher than the shown in this study. The141/616(22.89\%, CI95\% 21.08-24.7) prevalence of quarter level mastitis in our study is in agreement with $20.04 \%$ from Hawassa of southern Ethiopia ${ }^{16}$ and $10-25 \%$ from different parts of the world. ${ }^{3}$ The variation in prevalence of mastitis in the present study and different parts of the country was influenced by both intrinsic factors of dairy cow and environmental risk factors of mastitis.

\section{Risk factors}

Management Risk factor: In the analysis of management factors $62.34 \%, 31.82 \%$ and $5.84 \%$ of lactating cow were respectively housed on either earth floors without shade, a concrete floor with shade or a stone floor with shade. Muddy walking surface is one of the predisposing causes for mastitis in the dairy cow. ${ }^{3,4}$ In the current study there is no statistically significant difference in the different housing system $(\mathrm{P}>0.05)$. The prevalence of mastitis is $100 \%(1 / 1), 53 \%(29 / 54)$ and $42.42 \%$ (42/99) under Intensive, semi intensive and extensive management system. Even though higher prevalence were reported in this study it was not statistically significant different. The result is contras- ting to the report of Sori et al. ${ }^{12}$ who reported statistically significant difference between different grazing systems. A high prevalence of mastitis under intensive and semi intensive management was previously reported from Southern Ethiopia. ${ }^{14}$ The absence of significant difference might be due to small number of animals in intensive management system. The current study also reported a higher prevalence of mastitis $57.14 \%$ on farms that did not wash their hand before milking than those that did wash their hands before milking $45.71 \%$.

\section{Cow level risk factors}

Lactation status: The prevalence of mastitis based on the stage of lactation was $34.21 \%, 38.24 \%$ and $56.1 \%$ in the $1^{\text {st }}, 2^{\text {nd }}$ and $3^{\text {rd }}$ trimester of lactation. Statistically significant difference in prevalence of the disease in the $3^{\text {rd }}$ trimester compared to the $1^{\text {st }}$ and $2^{\text {nd }}$ trimester $(\mathrm{P}<0.05)$ was similar to other findings in the country. ${ }^{15,17}$ The high prevalence of mastitis in older dairy cattle compared to young and adult cows is associated with an increased period of exposure of the udder during previous lactations. ${ }^{4}$

Breed: Prevalence of mastitis was $38.2 \%(32.17-44.23)$ in local breeds and 58.46\%(CI95\% 49.23-67.69) in cross breeds. There was a statistically significant difference in the prevalence of mastitis between breeds $\left(\mathrm{x}^{2}=6.193, \mathrm{P}<0.01\right)$. In Ethiopia many studies showed statistically significant difference in mastitis between local and cross breeds..$^{12,14,15,17}$ Cows with high milk yield is also more susceptible to mastitis where as low-yielding cows tend to be more resistant. Genetic improvement for milk yield is accompanied by gradual decline in genetic resistance to mastitis. ${ }^{3}$

Age: In the current study the prevalence of mastitis was $34.15 \%$ (CI95\%, 28.75-39.54), 36.96\% (CI95\%, 31.12-42.79) and 61.16\%( CI95\%, 51.53-70.86) for young (2.5-6), adult (6-9.5) and $>9.5$ (older) cows respectively. The statistical analysis showed that there is a significant difference between older and younger aged cows $(\mathrm{P}<0.01)$. In Ethiopia high prevalence of mastitis in old animals were reported by Biffa et al. ${ }^{14}$ Mekibib et al. ${ }^{13}$ Bedacha \& Menghistu. ${ }^{17}$ The high prevalence of the disease in older animals related to the physiology of threat 
canal which is more dilated and remains partially open due to years of repeated milking. This facilitates the entrance of environmental and skin-associated microorganisms leading clinical or sub clinical mastitis. ${ }^{3,18}$ Blowey \& Edmondson ${ }^{4}$ also reported the high occurrence of mastitis in older aged cows compared to young and adult cattle. This could be due to damage of teat canals in old animals facilitates access of bacteria into the mammary gland.

Financial losses: In the current study mastitis causes both direct and indirect economic losses. Direct economic losses are associated with discarded milk during treatment and drug withdrawal, and cost of drugs of treatment. The indirect cost is related to decreased milk production because of udder damage. In Ethiopia many studies conducted were concentrated on determination of prevalence, risk factors and pathogen identification ${ }^{12-17}$ but did not report on its financial burden. This study shows that the disease caused a total loss of 2,949.08USD in a total of 89 local and 65 cross breed dairy cows. ${ }^{19-21}$ The disease caused annual production losses of $22.3 \%$ in cross breed cows and $2.24 \%$ in local breed lactating cows in the production cycle in one year. Other studies reported the economic effect of both direct and indirect effect of mastitis in different parts of the world. ${ }^{3,4}$

\section{Conclusion and recommendation}

The study showed existence of subclinical and clinical mastitis in the area. Breed, age and lactation status were statistically significant risk factors for the occurrence of mastitis. The study also revealed that most lactating cows are kept in poor husbandry management. In this finding, 2,949.08USD losses were incurred due to discarding of $5,097.59 \mathrm{Lt}$ milk that resulted in average market price of 2,643.20USD and 305.88 USD due to expense to drugs. The understanding of farmers on cause and transmission of Mastitis is poor. As well, the farmers requires awareness on housing system, disease cause and transmission. Since there is no national or farm level controls program for the disease the following recommendations have been suggested. Awareness creation for the dairy cow owners on housing and management of dairy cattle, sources of mastitis pathogen and transmission methods of mastitis causing agent to reduce disease prevalence and prevent occurrence of disease. The policy makers should design control methods through vaccination for highly pathogenic agent and develop guideline for dairy production management in the country. Since this is the first report from the study area further investigation is recommended.

\section{Acknowledgments}

The authors are greatly thankful to Wollega University for providing financial support. The authors appreciate the support and understanding of Fincha and Shambu town small holder dairy. Our especial thank has goes to the staff of HoroGuduru Animal production and Research Center of Wollega University.

\section{Ethical issue}

The aim of the study was to determine prevalence risk factor and economic importance of mastitis. It was designed and conducted through Questioner and detection of milk sample. Therefore, there is no any experiment done on animals under laboratory or field study. The response of the owners was based on their knowledge about the disease, personal willingness and critical reason to justify the clinical characteristics of the disease. The confidential issue of individuals were kept in secrete as to the standards.

\section{Conflict of interest}

Author declares that there is no conflict of interest.

\section{References}

1. Almaw G, Zerihun A, Asfaw Y. Bovine mastitis and its association with selected risk factors in smallholder dairy farms in and around BahirDar, Ethiopia. Trop Anim Health Prod. 2008;40(6):427-432.

2. Quinn PJ, Markey BK, Carter ME, et al. Veterinary Microbiology and Microbial disease. Massachusetts: Black Well Publisher; 2003. p. 402-408.

3. Radostits OM, Gay CC, Hinchcliff KW, et al. Veterinary Medicine. Text books of the disease of Cattle, Sheep, Pigs, goats and Horses. 10th ed. UK: Elsevier; 2008. p. 673-680.

4. Blowey R, Edmondson P. Mastitis Control in Dairy Herds. 2nd ed. UK: CAB. International; 2010.

5. Andrews AH, Blowey RW, Boyd H, et al. Bovine Medicine. Diseases and Husbandry of Cattle. 2nd ed. UK: Blackwell Science Publisher; 2004. p. 700-708.

6. Dohoo I, Martin W, Stryhn H. Veterinary Epidemiologic Research. AVC Inc. Charlottetown, Canada; 2003.

7. Pandey GS, Voskuil GCJ. Manual on milk safety, quality and hygiene for dairy Extension. Golden Valley Agricultural Research Trust. Zambia; 2011. p. 1-52.

8. Gari G, Bonnet P, Roger F, et al. Epidemiological aspects and Financial Impact of Lumpy Skin Disease in Ethiopia. Prev Vet Med. 2011;102(4):274-283.

9. Girma S, Mammo A, Bogele K, et al. Study on prevalence of bovine mastitis and its major causative agents in West Harerghe zone, Doba district, Ethiopia. Journal of Veterinary Medicine and Animal Health. 2012;4(8):116-123.

10. Putt SH, Shaw APM, Woods AJ, et al. Veterinary Epidemiology and Economics in Africa. Manual for use in the design and appraisal of Livestock Health. 2nd ed. Berkishare, England; 1998. p. 83-103.

11. Rushton J. The Economics of Animal Health and Production. London, UK: CAB International; 2009;279:295-299.

12. Sori H, Zerihun A, Abdicho S. Dairy Cattle Mastitis In and Around Sebeta, Ethiopia. International. Journal of Applied Research in Veterinary Medicine. 2005;3(4):32-38.

13. Mekibib B, Furgasa M, Abunna F, et al. Bovine Mastitis: Prevalence, Risk Factors and Major Pathogens in Dairy Farms of Holeta Town, Central Ethiopia. Veterinary World. 2010;3(9):397-403.

14. Biffa D, Debela E, Beyene F. Prevalence and Risk Factors of Mastitis in Lactating Dairy Cows in Southern Ethiopia. International Journal of Applied Research of Veterinary Medicine. 2005;3(3):189-198.

15. Moges N, Hailemariam T, Fentahun T, et al. Bovine Mastitis and Associated Risk Factors in Small Holder Lactating Dairy Farms in Hawassa, Southern Ethiopia. Global Veterinaria. 2012;9(4):441-446.

16. Megersa B, Manedo A, Abera M, et al. Mastitis in Lactating Cows at Hawassa Town: Prevalence, Risk Factors, Major Bacterial Causes and Treatment Response to Routinely Used Antibiotics. American-Eurasian Journal of Scientific Research. 2012;7(2):86-91.

17. Bedacha BD, Menghistu HT. Study on Prevalence of Mastitis and its Associated Risk Factors in Lactating dairy Cows in Batu and its Environs, Ethiopia. Global Veterinaria. 2011;7(6):632-637. 
18. Shittu A, Abdullahi J, Jibril A, et al. Sub-clinical mastitis and associated risk factors on lactating cows in the Savannah Region of Nigeria. $B M C$ Vet Res. 2012;8(134):1-8.

19. CSA. Federal Democratic Republic of Ethiopia, Central Statistical Agency. Agricultural sampling Survey: Livestock and Livestock characteristics. 505 statistical Bulletin, Addis Ababa, Ethiopia; 2011:35-40.
20. Grimes DA, Schulz KF. Bias and causal associations in observational research. Lancet. 2002;359(9302):248-252.

21. Nielsen C. Economic Impact of Mastitis in Dairy Cows. Faculty of Veterinary Medicine and Animal Science Department of Animal Breeding and Genetics Uppsala. Doctoral Thesis. 2009. 